\title{
Fuzzy Stochastic Capacitated Vehicle Routing Problem and Its Applications
}

Dr. Vishnu Pratap Singh ${ }^{1}$, Kirti Sharma ${ }^{2}$, and Debjani Chakraborty ${ }^{3}$

${ }^{1}$ Affiliation not available

${ }^{2}$ Department of Mathematics, VNIT Nagpur

${ }^{3}$ Department of Mathematics, IIT Kharagpur

November 26, 2020

\section{Hosted file}

FSCVRP.pdf available at https://authorea.com/users/373415/articles/495306-fuzzy-stochasticcapacitated-vehicle-routing-problem-and-its-applications 